\title{
Application of DC Magnetron Sputtering for Creation of Gas-Sensitive Indium Oxide Thin Films and Their Properties
}

\author{
V. LUHIN ${ }^{a} *$, I. ZHARSKY ${ }^{a}$ AND P. ZHUKOWSKI ${ }^{b}$ \\ ${ }^{a}$ Belarusian State University of Technology, Sverdlova 13a, 220050 Minsk, Republic of Belarus \\ ${ }^{b}$ Lublin University of Technology, Nadbystrzycka 38a, 20-618 Lublin, Poland
}

In this paper the technology of gas sensitive semiconductor structures based on indium oxide thin films by DC magnetron sputtering of indium with the subsequent thermal oxidation is developed. Structure, surface morphology and chemical composition of the obtained films have been investigated by electron diffraction, scanning electron microscopy, Auger electron spectroscopy, and X-ray photoelectron spectroscopy. Conditions of $\mathrm{In}_{2} \mathrm{O}_{3}$ films formation with high selectivity and sensitivity to $\mathrm{NO}_{2}$, and $\mathrm{NH}_{3}$ are established.

DOI: 10.12693 /APhysPolA.123.837

PACS: $81.15 . \mathrm{Cd}, 73.50 .-\mathrm{h}$

\section{Introduction}

At present time thin indium oxide films are widely applied to formation of transparent coverings, heterogeneous catalysts, IR-reflectors, monochromators, solar cells, photoelectrochemical electrodes, MOS-structures, heterojunctions, etc.

The use of indium oxide as a gas-sensitive material is restrained by high "quasimetallic" conductivity and low selectivity. In view of an opportunity of sensitivity and selectivity increase by modification of chemical composition and structure, the interest in $\operatorname{In}_{2} \mathrm{O}_{3}$ films has recently increased.

\section{Experimental details and results}

Thin $\mathrm{In}_{2} \mathrm{O}_{3}$ films have been obtained by thermal oxidation of thin indium films, formed by the DC magnetron sputtering method. Deposition of indium films was carried out in the vacuum universal system VUP-5M. As an etchant gas there was used argon, with a pressure of $\approx 0.1-1 \mathrm{~Pa}$ in the process of sputtering. The analytical grade indium metal target was used as the cathode. The target sputtering was carried out at an accelerating voltage of $0.5 \mathrm{kV}$; the discharge current was $0.15 \mathrm{~A}$. The indium films were deposited on single-crystal silicon wafers coated with dielectric layer $\mathrm{SiO}_{2}, \mathrm{Al}_{2} \mathrm{O}_{3}$, or muscovite mica $\mathrm{KNa}_{3} \mathrm{Al}_{3} \mathrm{Si}_{3} \mathrm{O}_{12}$. After the deposition of metallic indium the films were oxidized in a muffle electric furnace in the non-isothermal regime: heating to a temperature of $500-600^{\circ} \mathrm{C}$ for $40-60 \mathrm{~min}$ and annealing in isothermal mode at $500^{\circ} \mathrm{C}$ and $600{ }^{\circ} \mathrm{C}$ for 60 min (temperature and oxidation time were chosen experimentally).

The film technology based on the method of thermal oxidation of a metal layer allows forming oxide layers with thickness from several nanometers to several hundred nanometers. A gas-sensitive layer thickness is the

\footnotetext{
*corresponding author; e-mail: luhin_valery@mail.ru
}

important factor determining metrological characteristics of sensors as with the decrease of a film thickness sensitivity and speed response of a sensor element increase. In this work the $\mathrm{In}_{2} \mathrm{O}_{3}$ films, $30-50 \mathrm{~nm}$ thick were investigated. The use of various conditions and temperature modes of oxidation allows to change structure, stoichiometry and composition of films and, as a consequence, its electrophysical and sensor properties.

Oxidation of metallic indium films was investigated by measuring the change in resistivity of the films in the process of their oxidation during heating in an oven at a temperature from 25 to $500{ }^{\circ} \mathrm{C}$ and annealing at $500{ }^{\circ} \mathrm{C}$ for $60 \mathrm{~min}$. The resistance of the film was measured using a two-probe method with direct current. Electrical contact with the film was made by means of thin film platinum electrodes and clamping of electrodes made of titanium coated with platinum. The film resistance was measured with the reference voltage of $0.1 \mathrm{~V}$. The current in the circuit was measured by the microammeter. The temperature value in the furnace was controlled by a chromel-alumel thermocouple, the working junction of which was placed in close proximity to the oxidized film.

The kinetic dependences of the temperature changes and resistivity of indium films in the process of oxidation are shown in Fig. 1. For heating there was used an electric resistance furnace of industrial production with automatic temperature regulation; one of the standard rates was chosen to achieve the desired temperature. As shown in Fig. 1, there is a gradual resistivity decrease from $0.0037 \Omega \mathrm{cm}$ (for the metallic indium film) to $0.00018 \Omega \mathrm{cm}$ at temperatures up to $310^{\circ} \mathrm{C}$. On heating the film in the temperature range $310-400^{\circ} \mathrm{C}$ there is a slight increase in resistivity. Above $t=400^{\circ} \mathrm{C}$ the resistivity increases faster with the dependence of resistance on temperature close to quadratic. After reaching a temperature of $500{ }^{\circ} \mathrm{C}$ and the transition to the isothermal regime resistivity increase is almost linear for $10-15 \mathrm{~min}$, after which the growth rate of resistance begins to decrease. Exposure at $500^{\circ} \mathrm{C}$ for $50-60$ min leads to stabilization of film electrical resistance (Fig. 1). This fact gives an indirect indication of the completion of the film 
oxidation process at a given temperature. As the operating temperature of the sensitive layers of semiconductor sensors based on adsorption-type indium oxide does not exceed $500^{\circ} \mathrm{C}$ (mostly $200-400^{\circ} \mathrm{C}$ ), we can assume the thermal stability of the films in the subsequent operation.

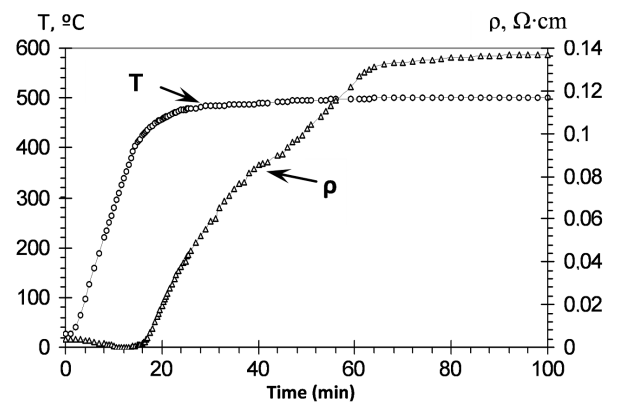

Fig. 1. Temperature and resistivity changes of a thin indium film during its thermal oxidation.

The phase structure and morphology of surface have been investigated by the electron diffraction methods using TEM H-800 (Hitachi) and SEM S-806. Analysis of electron diffraction patterns shows that the only identifiable crystal phase in the process of oxidation and in the oxide films is a cubic phase with a polycrystalline structure of $\mathrm{In}_{2} \mathrm{O}_{3}$ (Fig. 2).

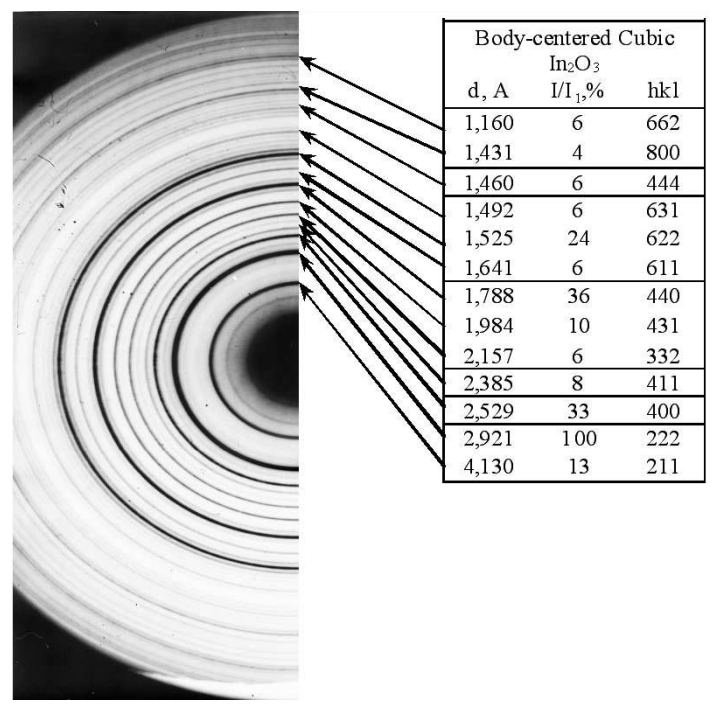

Fig. 2. Electron diffractogram of $\operatorname{In}_{2} \mathrm{O}_{3}$ films.

The indium films deposited on silicon are characterized by the pronounced grain structure (Fig. 3) with a particle size ranging from 10 to $70 \mathrm{~nm}$, the bulk $(80 \%)$ accounting for the interval from 15 to $50 \mathrm{~nm}$ (Fig. 4a). Formation of oxide film on the silicon substrate is accompanied by a decrease in the amount of fine particles and the increased content of particles of larger size, the bulk of which $(\approx 80 \%)$ is in the range of $20-55 \mathrm{~nm}$, with the maximum in the range of $30-35 \mathrm{~nm}$ (Fig. 4b).

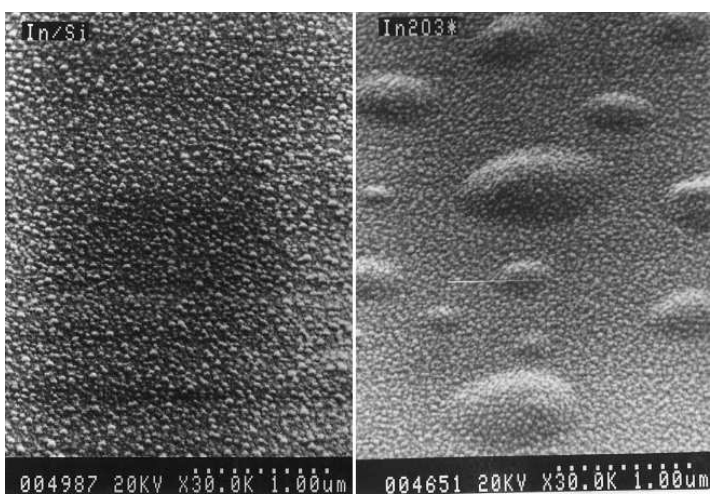

Fig. 3. SEM images of indium and indium oxide films (magnification is 30,000 ).

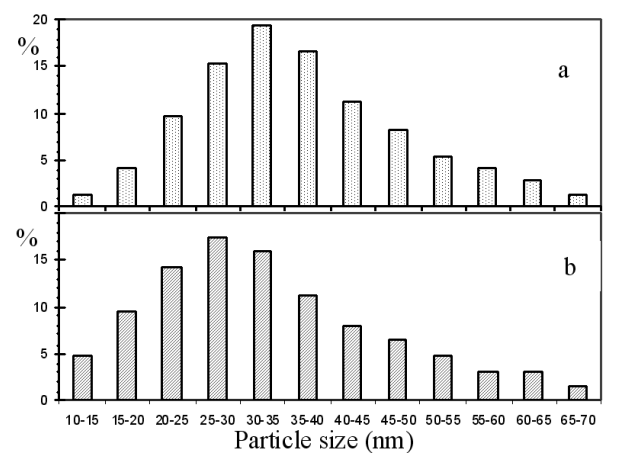

Fig. 4. Particle size distribution in indium (a) and indium oxide (b) films.

The elemental composition of $\operatorname{In}_{2} \mathrm{O}_{3}$ films surface has been studied by the Auger electron spectroscopy using the AES spectrometer PHI-660 (Perkin Elmer). Electron shells of atoms were excited by the primary electron beam with the $2000 \mathrm{eV}$ energy. Locality in the depth analysis is $\approx 3 \mathrm{~nm}$, scan area $\approx 1 \mathrm{~mm}^{2}$. The depth distribution of the film composition is investigated by $3.5 \mathrm{keV}$ Ar-ions sputtering with the registration of the Auger electrons $K L_{23} L_{23}$ - transition for oxygen and $M_{4} N_{45} N_{45}$ - transition for indium. The quantitative analysis is performed by the pure standards method, by which the Auger electron current intensity is adjusted by a factor related to the Auger spectrometer sensitivity.

The elemental composition profiles of the $\mathrm{In}_{2} \mathrm{O}_{3}$ film thickness on the $\mathrm{Si}$ substrate are presented in Fig. 5. The indium and oxygen distribution in the film thickness is uneven. The stoichiometry coefficient in the surface layer defined by the escape depth of the Auger electrons $\approx 5 \mathrm{~nm}$ is 1.41 . With the surface sputtering to a depth of $5-10 \mathrm{~nm}$ the stoichiometric ratio is 1.31 .

The chemical composition and state of the $\mathrm{In}_{2} \mathrm{O}_{3}$ film surface elements are investigated by X-ray photoelectron spectroscopy (XPS). XPS spectra were recorded with a multipurpose electron spectrometer PHI 5700 (Perkin Elmer). Chemical status of indium and oxygen was determined by the binding energies of the photoelectron lines of In $3 d_{5 / 2}$, In $3 d_{3 / 2}$ and O $1 s$ (Fig. 6). 


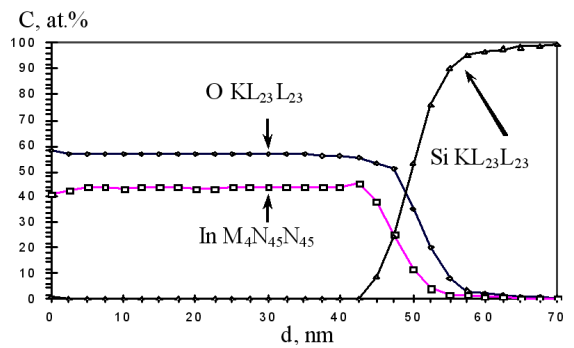

Fig. 5. AES profile of elements distribution in $\operatorname{In}_{2} \mathrm{O}_{3}$ films deposited on silicon.

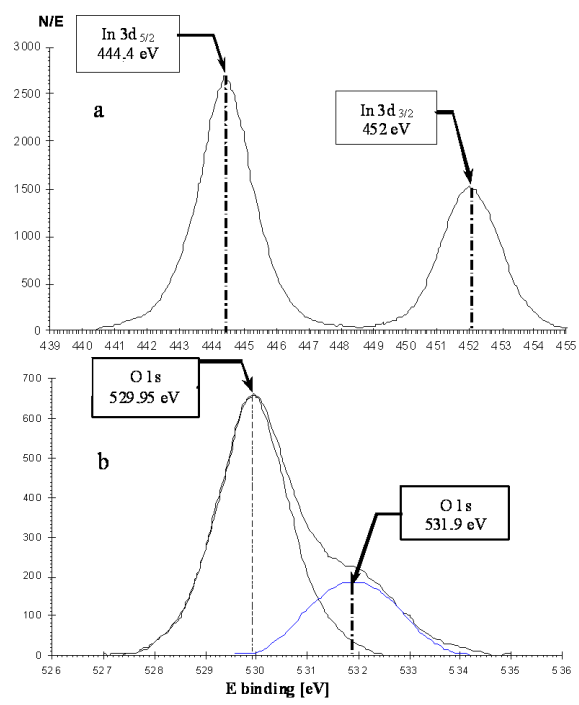

Fig. 6. XPS spectra of indium (a) and oxygen (b) on the surface of $\operatorname{In}_{2} \mathrm{O}_{3}$ films.

XPS spectrum of indium is characterized by the presence of two spectral lines with the binding energies of 444.4 and $452 \mathrm{eV}$ (Fig. 6a), due to multiplet splitting of the $3 d$ level. The chemical shift of the line In $3 d_{5 / 2}$ in the oxide film relative to the $\operatorname{In}^{0}$ (reference data for the average binding energy of $443.5 \mathrm{eV}$ ) is $0.9 \mathrm{eV}$, which can be attributed to the state of $\mathrm{In}^{3+}$ (change in the binding energy of the oxidation of $\operatorname{In}, \operatorname{In}_{2} \mathrm{O}_{3}$, based on the reference data, is $+0.8-1.2 \mathrm{eV})$.

The oxygen photoelectron line is shown in Fig. $6 \mathrm{~b}$. Oxygen peak has a pronounced asymmetry, indicating the presence of overlapping components that differ in energy, shape and intensity, with the binding energies of $529.95 \mathrm{eV}$ and $531.9 \mathrm{eV}$. The photoelectron line with $E_{\mathrm{b}}=529.95 \mathrm{eV}$ has higher intensity and corresponds to the oxygen lattice state (reference data for the average $\mathrm{O}^{2-}$ binding energy in the $\mathrm{In}_{2} \mathrm{O}_{3}$ compound is $530 \mathrm{eV}$, and varies from 529.1 to $530.9 \mathrm{eV}$ ). The broad envelope of the photoelectron $\mathrm{O} 1 s$ lines in the range $531-534.5 \mathrm{eV}$ is associated with a sufficiently large number of oxygen and its compounds adsorbed on the surface. The photoelectron line with a binding energy of $531.9 \mathrm{eV}$ may correspond to the surface adsorbed oxygen in various forms, as well as to the oxygen incorporated in a hydroxyl group.
In addition, the surface of the $\operatorname{In}_{2} \mathrm{O}_{3}$ film contained a small amount of chemisorbed water, which may indicate a small plateau of the total XPS-peak, protruding above the background of the binding energies of $533-534 \mathrm{eV}$, but the concentration is negligible.

Calculation of the indium-oxygen stoichiometric ratio depending on the intensities of photoelectron lines and the relative photoionization cross-sections $\left(\mathrm{S}\left(\operatorname{In} 3 d_{5 / 2}\right)=\right.$ $13.2 ; \mathrm{S}(\mathrm{O} 1 s)=2.85)$ shows that the stoichiometric ratio of elements is 1.13. The stoichiometric ratio, calculated from the total intensity of the two photoelectron lines of oxygen $\left(\sum I \mathrm{O} 1 s=840\right)$ is 1.45 , which agrees with the value obtained by the AES. The ratio of the intensity of the $\mathrm{O} 1 \mathrm{~s}$ binding energy $531.9 \mathrm{eV}$ to the total intensity of the two oxygen photoelectron lines, shows that $\approx 22 \%$ oxygen in the surface layer of the $\mathrm{In}_{2} \mathrm{O}_{3}$ film is in the adsorbed state, or incorporated into the hydroxyl groups.

Gas sensitive properties of indium oxide sensor element have been investigated with respect to ammonia and nitrogen dioxide. The $\operatorname{In}_{2} \mathrm{O}_{3}$ films obtained by oxidation at $500{ }^{\circ} \mathrm{C}$ for $1 \mathrm{~h}$, showed a high sensitivity of the thermo-EMF in the detection of low concentrations of ammonia. The impact on the sensor with air mixture containing ammonia, results in the increasing thermoelectric power value at a constant temperature difference between the contacts. Studies of sensor properties of these films in the detection of low concentrations of $\mathrm{NO}_{2}$ showed no significant sensitivity of the thermo-EMF to the content of $\mathrm{NO}_{2}$ in air. As shown by the electrophysical properties of the $\mathrm{In}_{2} \mathrm{O}_{3}$ films, obtained by different modes of oxidation, the increase in temperature oxidation of the In films from 500 to $600{ }^{\circ} \mathrm{C}$ leads to an increase in films resistivity, the Seebeck coefficient and sensitivity to $\mathrm{NO}_{2}$ $[1,2]$.

\section{Conclusion}

The process of indium oxide films formation was studied by measuring the resistivity of indium films in the process of oxidation. The structure and chemical composition of the obtained films were investigated using the methods of electron diffraction, scanning electron microscopy, Auger electron and X-ray photoelectron spectroscopy. The vacuum technology of thin indium oxide films formation with thermoelectric parameters, sensitive to the composition of the environment, by magnetron sputtering metal source, followed by thermal oxidation is developed. The obtained results can be used in microelectronic sensor analyzers.

\section{References}

[1] V. Luhin, V. Zarapin, I.M. Zharsky, P. Zukovski, M. Kolasik, C. Kozak, Elektronika - Konstrukcje Technologie Zastosowania 6, 262 (2008) (in Polish).

[2] V. Luhin, I.M. Zharsky, P. Zukovski, J. Partyka, Przeglad Elektrotechniczny 84, 174 (2008) (in Polish). 